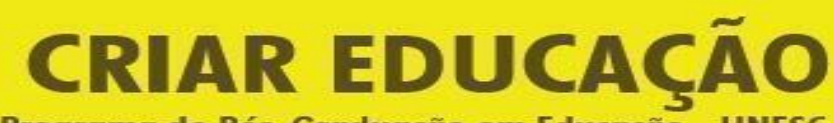

Revista do Programa de Pós-Graduação em Educação - UNESC

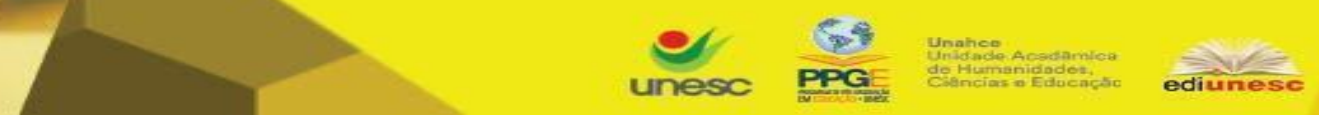

Criar Educação, Criciúma, v. 9, № 3, ago/dez. 2020 - PPGE - UNESC - ISSN 2317-2452

\title{
COMO NARRAR O CORPO MÍNIMO?
}

\section{Adriana Barin de Azevedo ${ }^{1}$}

Resumo: Este texto questiona a respeito do que nos tornamos sensíveis neste momento de pandemia, com o isolamento e os impedimentos presentes. Pretende-se acessar o que chamaremos de um corpo mínimo, ou seja, os gestos de um corpo que indicam sua capacidade singular de afetar e ser afetado. Para tanto, torna-se necessário aprender a narrar os mínimos gestos deste corpo, a partir da esquiva do entulho de notícias explicativas e de interpretações, na esteira de Fernand Deligny e Walter Benjamin, para conservar uma memória da coexistência de infinitos modos de viver.

Palavras-chave: narrativa, corpo mínimo, Deligny, afetos, pandemia.

\section{HOW TO NARRATE THE MINIMUM BODY?}

\begin{abstract}
The text proposes a question on what, in this pandemic moment with isolation and current restraints, make us sensible to get to know what we call the minimum body: the gestures of a body which indicate its singular capacity of affecting and being affected. To do so, one must learn to narrate this body's minimum gestures through the escape of a pile of news texts and interpretations, based on Fernand Deligny and Walter Benjamin, to explore a coexistence memory of endless ways of living.
\end{abstract}

Keywords: narrative, minimum body, Deligny, affection, pandemic.

\section{Introdução}

Isso que eu escrevo, eu não pretendo apagar. Os traços ali persistem mesmo que não sejam lidos (DELIGNY, 2007, p. 1089, tradução livre).

Talvez possamos sustentar uma afirmação de que o corpo mais real e concreto, neste momento de pandemia, seja o corpo das palavras. São elas que vão nos ajudar a lembrar dos sentidos que sofreram maior interdição, como é o caso do tato. Tocamos menos nas coisas e nas pessoas. Com abraços e beijos limitados aos

\footnotetext{
1 Professora Adjunta do Departamento de Psicologia da UEM, Av. Colombo, 5790. Maringá - PR. Email: abazevedo@uem.br
} 
Criar Educação, Criciúma, v. 9, ํo 3, ago/dez. 2020 - PPGE - UNESC - ISSN 2317-2452

mais próximos e com encontros vividos a certa distância, submetemos a pele ao contato mais frio e asséptico do cloro e do álcool em gel.

De todo modo, o corpo presente das palavras pode conservar em nós uma memória dos sujeitos com os quais já convivemos invocando imagens, sons, cheiros e aquilo que um dia foi possível sentir pela pele em contato com as coisas, as pessoas, o mundo. Se há então, uma memória que se conserva, interessa perguntar o que estamos priorizando no campo das lembranças e, nesse sentido, o que estamos dispostos a esquecer ${ }^{2}$. Podemos pensar, por exemplo, o quanto seria interessante legar ao esquecimento nosso apego aos hábitos de um mundo produtivo, no qual sustentávamos a ilusão de controlar a natureza como senhores em um império (ESPINOSA, 2018).

A pergunta pelo que conservar e pelo que desapegar, ou pelo que lembrar e pelo que esquecer, pode ser reformulada considerando o modo como contamos, como enunciamos as palavras que expressam as histórias vividas no presente. Nossa questão é, portanto, saber como narramos as imagens, sons, toques que duram em nós, conservando a intensidade da experiência atual sem nos limitarmos a explicações reducionistas desta experiência.

Com esta pergunta estamos, de algum modo, fazendo um convite a entrar em contato com uma dimensão do vivido no corpo, aprendendo a narrar o modo em que este corpo compõe uma memória. Para tanto, é necessário um exercício de deslocamento do enunciado a respeito do vivido. Narrar envolve um ato distinto do discurso egóico, das queixas pessoais, de um enunciado ressentido que costuma "acusar [algo ou alguém] toda vez que o efeito sofrido [no corpo] se mostra contrário e lhe revela a sua própria impotência" (DELEUZE, 2002, p.29). A narrativa também se diferencia das "traduções" do vivido do corpo na linguagem dos diagnósticos identitários que classificam os sujeitos a partir de modelos transcendentes, em especial aqueles relativos à performance e à produção.

De que narrativa, então, estamos tratando aqui? Estamos perseguindo 0 convite ou, melhor dizendo, a convocação de Walter Benjamin (1986), para

\footnotetext{
${ }^{2}$ A relação entre uma memória que pode lembrar e esquecer é inspirada na crônica de Eliane Brum a respeito do filme "E se vivêssemos todos juntos?" publicada no livro A menina quebrada e outras colunas. Porto Alegre: Arquipélago Editorial, 2013.
} 
de um corpo e sua capacidade de composição pretende-se fazer durar? Digamos que a vida que tem se mostrado ameaçada é a vida do corpo biológico, que pode ser destruído pelo vírus, mas é também a vida do corpo afetivo, que diante das reconfigurações dos modos de viver, relacionados ao trabalho, ao isolamento, as perdas, aos impedimentos, a padecimentos de todos os tipos, também está fragilizada e de certo modo destruída.

Sugerimos pensar que há certa condição de corpo a ser garantida para conservar a vida. Um corpo capaz, como dizia Canguilhem (2017) de inventar novas normas para a vida quando o meio em que ele se encontra se mostra infiel com a presença do vírus, se mostra contrário a seu modo de existir. Esta condição de corpo que é preciso garantir e que envolve o corpo biológico e o corpo afetivo, mas do qual pouco tratamos é o que chamaremos aqui de corpo mínimo.

Proponho, portanto, investigar, o que podemos denominar uma condição mínima do corpo, que se remete a uma singularidade afetiva, a qual não se limita a um estado respondente, funcional, produtivo, reativo. Uma singularidade que por vezes se afirma em sua inadaptação, precariedade e que em seus diversos modos de se exprimir carrega camadas de sensibilidade ainda desconhecidas. Para conhecer 0 que estamos chamando de corpo mínimo parece ser preciso reaprender a narrá-lo.

\section{A que somos sensíveis nos territórios da pandemia?}

A partir de experiências vividas, neste período de pandemia, em diferentes espaços - atuando como tutora em uma Residência Multiprofissional, oferecendo grupos de estudo e de partilha de experiências, participando de grupos de pesquisa com outros docentes, estudantes e trabalhadores de saúde que tem relatado suas vivências, proponho pensar de que modo um corpo mínimo se apresenta.

Estudantes e colegas de trabalho relatam com frequência o impacto da experiência de distanciamento daqueles com quem conviviam, o impedimento do abraço e do toque e a substituição dos encontros presenciais por conversas virtuais, nas quais o outro se apresenta em uma nova modalidade de imagem, som, escrita. Parecem se esboçar novas sensações nos corpos provocadas também pela mudança de sentido em relação ao que é próximo e distante. 
Como sugere Bezerra Jr. (2010) e outros autores (ORTEGA, 2008; EHRENBERG, 2010), desde meados de 1980, já vivíamos esta experiência com o avanço tecnológico, que mudou os modos de organizar o cotidiano de trabalho, de lazer, das relações afetivas a partir das novas ferramentas de comunicação com aplicativos em celulares, notebooks, tablets, como whatsapp, instagram, facebook, tinder, entre outros, assim como os novos modelos de partilha de conhecimento, ou talvez, de informação, que aparece em formatos como podcasts, vídeos gravados, composições virtuais de diferentes tipos.

Há algum tempo, fomos iniciados, na experiência de viver distantes das pessoas fisicamente próximas e, através das plataformas virtuais, de ficar próximos das pessoas fisicamente distantes. Talvez nosso estranhamento da experiência presente esteja mais relacionado ao fato de não podermos partilhar o mesmo espaço com outros corpos, embora já estejamos habituados a viver distantes uns dos outros, muitas vezes numa condição de indiferença com aqueles que partilham o mesmo território. Estes outros estavam ao nosso lado, agora não estão mais. Por isso, podemos pensar que há uma nova condição de distanciamento físico que exige uma pergunta ao que nos tornamos sensíveis. Será que, com a pandemia, ao sermos forçados a nos separar e modificar boa parte dos hábitos que tínhamos e experimentar o corpo em novas relações, acessaremos outras camadas de nossa sensibilidade?

Talvez não se trate de uma pergunta simples de se fazer, já que, poderíamos dizer, há uma invasão de respostas que se antecipam à pergunta. Não somos capazes de atentar a nossa sensibilidade quando nossos corpos e mentes são bombardeados com informações de todos os tipos ininterruptamente. Grande parte são informações relativas às preocupações com a segurança e proteção com equipamentos, hábitos, comportamentos, etc.; são informações que atualizam os efeitos do caos no mundo, pelo número de mortes e as atitudes assustadoras dos chefes de Estado; informações que indicam evoluções no campo das pesquisas na intensa corrida da ciência contra a morte da humanidade. Além disso, o conjunto de informações que recebemos chegam com inúmeras explicações a respeito dos sentidos e significados do que estamos sentindo e sobre a mudança na condição de sujeitos que estamos em vias de nos tornar. Diríamos se tratar, portanto, em uma expressão que as resume, de informações medicalizadas, já que elas têm o diagnóstico e a terapêutica explicada e 
Criar Educação, Criciúma, v. 9, ํo 3, ago/dez. 2020 - PPGE - UNESC - ISSN 2317-2452

definida para a produção de novos modos hegemônicos de subjetivação. Podemos dizer que este bombardeio comunicativo, que é um modo de medicalização da vida, não começa com a situação de pandemia, mas parece se exacerbar com ela.

Tentando traduzir a experiência com estes dados informativos e análises que tentam dar contorno, lugar, amparo ao nosso sofrimento e manter em pé um sujeito ou modo de vida que parece se despedaçar, podemos dizer que abrimos mão ou que terceirizamos a nossa capacidade de fazer contato com o que sentimos. Talvez uma das maiores restrições a que somos submetidos esteja em acessar o corpo mínimo, ou seja, o gesto mínimo de um corpo em sua singularidade de afetar e ser afetado pelo mundo.

\section{Seguir o rastro da narrativa}

As histórias, desde o início da humanidade, foram rabiscadas, pintadas nas paredes das cavernas, narradas pelo traço da imagem, pelas pegadas no solo, pelos instrumentos que não se cansaram de ecoar as músicas de muitos tempos.

Com traços, riscos, rabiscos, marcas e objetos que compõem um território e uma época, narramos modos de existência. Através destes traços, destes modos de contar uma história damos visibilidade a um ethos de um lugar e de um tempo e por vezes fazemos um retrato geral do que seria um modo de vida ancestral, arcaico, medieval, moderno, produtivo-neoliberal, etc.

Estas categorias que localizam e definem modos de vida necessariamente restringem e, talvez se possa dizer, ignoram, aniquilam, esquecem, desconsideram a multiplicidade em que tais vidas se apresentam. Talvez possamos dizer que elegemos alguns traços e os definimos, mas precisamos considerar que coexistem com estes infinitos outros.

Quando nos ocupamos do modo como um corpo se apresenta em sua capacidade singular de afetar e ser afetado, nos aproximamos desta multiplicidade de modos de existir que precisam ter suas histórias ouvidas e narradas. 
Criar Educação, Criciúma, v. 9, ํo 3, ago/dez. 2020 - PPGE - UNESC - ISSN 2317-2452

Tomarei como exemplo disparador para investigar o que estamos compreendendo como corpo mínimo uma situação de vida de uma paciente ${ }^{3}$ que se encontrava hospitalizada, devido a um Acidente Vascular Cerebral que Ihe provocou a perda de todos os movimentos do corpo, não podendo se mexer, nem falar, de modo que sua capacidade de comunicação com o mundo fora reduzida quase por completo. Seu único modo de contato se ensaiava pelo movimento do globo ocular, através de um olhar que parecia tocar o outro, se aproximar dele, estabelecer algum tipo de encontro que indicasse sua permanência ali, estando presente no silêncio e na ausência do seu gesto. Pensando na singularidade do estado vivido por este corpo, podemos nos questionar quantas camadas de sensibilidade cabem naqueles olhos? O que estes olhos veem, sentem, o que dizem, no que tocam? Que modo de existência eles tentam ou conseguem sustentar?

Partindo desta situação que se apresenta como um dos impedimentos mais extremos de um corpo, procuro ouvir outras narrativas de colegas docentes, de discentes, de grupos de pesquisa, de trabalhadores de serviços de saúde, de amigos. As diferentes vozes verbalizadas e escritas indicam que muitas mudanças no corpo estão sendo sentidas e percebidas.

Penso também nas minhas sensações neste contexto. O desejo de estar perto de pessoas queridas muitas vezes se realiza através dos sonhos noturnos que acolhem melhor a dimensão do encontro do que os dispositivos virtuais de áudio e vídeo que, com o excesso de uso, tornaram menos disponíveis os sentidos da visão e da audição.

Além disso, os encontros também acontecem quando acionamos nosso gesto solitário de nos comunicar com outros através do pensamento. Lembrando de situações e de pessoas tentamos narrar um encontro afetivo, conservar em nós o valor destes encontros. Será que, a paciente com AVC também experimenta este gesto do pensamento, como um de seus mínimos recursos, sustentando este encontro à distância, que ainda a aproxima das suas relações e do seu lugar no mundo?

\footnotetext{
${ }^{3}$ Refiro-me a uma situação acompanhada e narrada por uma das residentes de uma Residência Multiprofissional em Saúde, com ênfase em Urgência e Emergência, da qual participo como tutora.
} 
Estas experiências e questionamentos expressam a nossa pergunta pela capacidade de traçar-escrever como modo de conservar as intensidades que habitam nosso corpo neste momento em que tantas atividades e hábitos estão suspensos. Como, cada um, com seus recursos, na singularidade em que vive esta experiência, acessa seus mínimos gestos e pode narrá-los? Seria o dispositivo da escrita um dos dispositivos capazes de auxiliar na seleção dos encontros, afastando os corpos de algumas notícias e os conectando a outra camada de suas histórias de vida neste momento de pandemia?

A experiência cotidiana nos mostra que não aguentamos viver tantos afetos contrários ao mesmo tempo. A cada dia nos embalamos com um contexto afetivo distinto de acordo com os encontros (em boa parte virtuais) que temos com as notícias ou com aqueles que estão próximos. A experiência da vida e da morte, que sempre nos acompanhou, parece ganhar outra velocidade e impacto diante da fatalidade do vírus. Parece que sentimos mais rapidamente ou com outra densidade os afetos daqueles que enterram seus mortos, vítimas do vírus, e estão em luto, e também daqueles que festejam os nascimentos ou criam estratégias de partilha e cuidado comum. Nós vivemos no corpo as oscilações destes afetos que se recombinam a cada nova situação do dia a dia no isolamento, das atuações na saúde, da vida nas ruas, dos encontros virtuais e da perda daqueles que estão perto e distantes de nós.

Por isso estamos interessados em olhar para o traço da escrita que talvez possa acessar de que modo se desenham os movimentos sutis do corpo nesta circunstância de pandemia. Interessa-nos perguntar qual é a memória que as palavras escritas são capazes de conservar? O toque e o gesto a serem registrados na escrita, que talvez possam também ser narrados pela fotografia, pela pintura, pela música, pelo cinema permitirão que viventes de um futuro distante os reencontrem.

Tomemos um exemplo da literatura que conserva a memória de uma intensidade vivida. Em uma bela imagem expressa por Dante Alighieri, em sua obraprima A Divina Comédia, partilhamos com o protagonista um encantamento diante das esculturas existentes na entrada do Purgatório. A sensação narrada por Dante e partilhada pelo leitor é a de que as esculturas estariam falando com ele. Uma escultura que representa o relato da Anunciação - o encontro do Anjo com a Virgem Maria - é, 
nas palavras do autor, de uma beleza impressionante que faria inveja a própria natureza:

\begin{abstract}
O anjo que veio à Terra co'o decreto da paz, tão lacrimada pela gente, que descerrou do Céu o longo veto, parecia tão real, à nossa frente, representando, em postura suave, não figurar só uma efígie silente. Ter-seia jurado que dissesse: 'Ave', pois também lá esculpida estava aquela que para o Supremo Amor girou a chave; impressa no ato era a palavra bela: 'Ecce antilla Dei', tão propriamente como na cera a figura se sela (ALIGUIERI, 2017, p.68).
\end{abstract}

Há uma memória afetiva que a arte da escultura e da literatura permitem ecoar e fazer durar. As esculturas do Purgatório que expressavam uma realidade viva acionavam certa vitalidade no corpo do protagonista. Seguindo por esta leitura, podemos observar qual memória do corpo temos tornando presente a partir dos afetos acionados pelas experiências em um contexto de pandemia. Embora, em momento algum, tenhamos parado de contar o que se passa conosco, poucas vezes conseguimos, de fato, narrar o corpo. Para narrar a intensidade do presente, o modo como sentimos e pensamos a pandemia é preciso encontrar palavras que não a reduzam a um conjunto de fatos explicáveis. De que modo então acessar o gesto artesanal da comunicação, de que fala Benjamin, ou contar mostrando a intensidade presente no corpo, como faz Dante, conservando assim a força de uma experiência vivida?

O que consideramos importante, na busca desta capacidade narrativa, é que o recolhimento ao qual a pandemia nos convidou se apresenta como uma oportunidade. Recolher-se pode permitir um contato com certa sensibilidade, com certa memória do corpo que não é aquela mais conhecida ou partilhada coletivamente. Trata-se de um recuo que faz ver uma capacidade de sentir que coexiste em nossas experiências, mas que não está enunciada ou é por vezes apagada.

Tomemos algumas situações para pensar no recolhimento dos corpos. No trabalho de alguns profissionais de saúde - que acompanho pela supervisão em alguns equipamentos e através de espaços de grupos de pesquisa - surge uma preocupação quanto a situação dos usuários que não podem receber a mesma oferta de cuidado devido ao contexto de pandemia, quando grande parte dos serviços realizados estão suspensos ou reduzidos. 
Um dos modos de cuidar está relacionado a oferta das atividades nos serviços de saúde e saúde mental, com a disponibilidade dos profissionais para atender, acolher, ouvir estes usuários garantindo uma rede mínima de sustentação vital. Com as restrições de contato referentes à pandemia e a redução de alguns modos de atendimento à população usuária destes serviços coloca-se em análise o risco de desassistência e fragilização da condição existencial destes usuários diante da ausência deste modo de cuidado. Tem aparecido, por exemplo, como efeito desta situação, um aumento do uso de medicação, que poderia estar atrelada à ausência de outras alternativas de cuidado como os espaços grupais, o contato com profissionais e outros usuários, assim como à ausência de percepção de outros recursos da capacidade afetiva para inventar outras saúdes em meio a esta situação.

A preocupação dos profissionais em relação aos usuários permite olhar para o modo como os corpos são afetados a partir deste recuo em relação aos espaços de cuidado. O que sente um corpo que é impedido de participar de grupos terapêuticos? Como este corpo reage a mudança de cuidado que funcionava por encontros presenciais e agora acontece, por exemplo, por teleatendimentos de psicologia? No caso de uma escuta e de uma fala que acontece por telefone, que novas nuances ganham a presença da voz como elemento disponível de cuidado?

Nestas situações próprias ao campo da saúde, assim como em outras situações que todos partilhamos pela ausência nos lugares de trabalho, de cuidado, de relação, parece que somos chamados a observar a presença de outros afetos, outra memória, outras camadas de sensibilidade.

A partir do que se mostra ausente, a pergunta por outros modos de cuidar é colocada. Recuar aparece, então, como um verbo que convida a visitar uma capacidade de afetar e ser afetado desconhecida em diversas formas de expressão. Deste modo, interessa olhar para esta variação afetiva dos usuários e o que é possível acessar, que não apenas o dispositivo da medicação ou a cronificação do sofrimento, em alguns casos. O que se acessa da própria sensibilidade quando não se tem acesso ao cuidado presencial dos profissionais? Quando um corpo não pode se expressar pela presença, pelo olhar e pela fala como fazemos para ouvi-lo a esta distância? Como usuários e profissionais, separados pela barreira do vírus, isolados, fechados 
Criar Educação, Criciúma, v. 9, nº 3, ago/dez. 2020 - PPGE - UNESC - ISSN 2317-2452

cada um nos seus espaços - sejam eles domiciliares ou nos próprios serviços de saúde - conservam uma memória afetiva de cuidado?

Assim como perguntamos a respeito do que lembrar e esquecer, ou seja, quais critérios, quais memórias nos interessam conservar, perguntamos também quais sensibilidades são priorizadas, selecionadas a partir deste recuo.

Segundo Espinosa (2018), temos uma grande capacidade de afetar e sermos afetados pelo mundo, e esta capacidade é conquistada no aprendizado dos nossos encontros. Cada corpo expressa uma potência de sentir e agir, sendo preenchido por afetos de todos os tipos. Cada mente expressa uma potência de pensar, preenchida por ideias que correspondem as afecções do corpo (ESPINOSA, 2018). Segundo este autor os modos singulares, como ele chama a nós humanos, são uma potência de pensar e agir, mente e corpo. No entanto, pouco se sabe desta potência, dos inúmeros universos afetivos que habitam um corpo e uma mente e, portanto, torna-se importante vasculhar os micromovimentos presentes neste momento de recuo e reinvenção do cotidiano.

A consígnia de Espinosa (2018) diz respeito aos modos de conhecer a nós mesmos e ao mundo aprendendo a respeito de nossa potência de pensar e agir a partir dos afetos que aumentam e diminuem esta potência. Segundo esta filosofia, os encontros que aumentam a potência de pensar e agir, são chamados alegres e os encontros que diminuem esta mesma potência, são chamados de encontros tristes. Nesse sentido, o que é alegre e triste na experiência do profissional, do usuário e da paciente é sempre distinto e singular. Em todos os casos, é apenas a partir dos encontros alegres, que é possível conhecer a respeito da própria capacidade afetiva que oscila em momentos de tristeza, fragilizações, perdas e também fortalecimentos e invenções que enfrentam às intercorrências vividas.

Os encontros que temos vivido neste momento retratam o que se mostra como alegria ou tristeza em nosso modo de existência. O que é alegria e tristeza neste momento para os profissionais de saúde, para os usuários que não podem ser cuidados como antes, para a paciente que se vê em um corpo totalmente distinto do que tinha?

Nas ausências e impedimentos da vida atual e na descoberta de outros afetos do corpo, começamos a perceber que pouco sabemos a respeito de nosso próprio 
Criar Educação, Criciúma, v. 9, ํo 3, ago/dez. 2020 - PPGE - UNESC - ISSN 2317-2452

corpo (ESPINOSA, 2018). Vamos percebendo também que há mínimos gestos que são continuamente aniquilados pelos modos mais hegemônicos de existir ou pouco visitados nas estratégias de cuidado que conhecíamos até agora.

Sugerimos, portanto, pensar que é a partir desta experiência de suspensão, vivida pela pandemia, desta exigência de se dar um passo atrás, que podemos narrar e, assim, conservar a memória dos gestos sutis, das mínimas variações do nosso corpo que indicam que nosso modo de existir pode se apresentar de muitas maneiras distintas.

\section{O corpo mínimo no rastro de Fernand Deligny}

Fernand Deligny (1913-1996) autor a quem é difícil atribuir um campo de atuação, mas que costumava se definir como etólogo e poeta (DELIGNY, 2007), pode trazer contribuições interessantes para pensarmos uma ideia de corpo mínimo, a partir de sua experiência de convívio com crianças autistas. Diríamos que este autor realiza um espécie de recuo no encontro com estas crianças, deslocando-se da posição de especialista, cuidador ou clínico e, deste modo, fazendo contato com certa sensibilidade de uma vida autista, considerada por ele, como distinta daquela do humano de linguagem, própria ao modo de vida partilhado pela maioria de nós. Este autor se interessava em observar o mínimo gesto do autista, expresso por uma delicadeza estranha a nossa compreensão habitual, e em composição com o território no qual é traçado.

Em uma região rural no sul da França, Deligny conviveu ao longo de alguns anos na companhia de crianças e adolescentes que eram classificados com o diagnóstico de autismo. O território, enquanto espaço físico habitado por adultos e crianças, que conviviam e partilhavam atividades próprias a uma vida no campo, organizava o corpo destas crianças, na medida em que elas ali repetiam sempre os mesmos movimentos e trajetos como que imantadas pelos traços do próprio território, traços estes muitas vezes invisíveis para nós.

O modo de existência destas crianças e adolescentes envolvia uma relação de composição com este território através do rastreio das coisas ali existentes, fossem elas pessoas, objetos, sons. Seus corpos entravam em relação com poucos 
elementos conectados, coisas e trajetos que delineavam um cotidiano de vida rural: cortar a lenha, fazer o pão, lavar a louça, buscar água no rio, conduzir as cabras e, a partir dos quais era possível produzir desvios.

Deligny (2007) aponta a importância da relação entre gesto e território, observando o corpo do autista numa condição existencial de precariedade material. Tratava-se de uma vida com elementos mínimos de sobrevivência. Uma circunstância em que todos os excessos estavam eliminados: um mínimo de variedade de alimentos, poucos objetos e quase nada de linguagem, já que a maioria destas crianças não falava, assim como Deligny e os outros que participavam desta rede de convivência reduziam a fala ao mínimo necessário. Afirmando este tipo de precariedade, Deligny exercitava também eliminar o excesso de interpretação sobre a vida singular destas crianças.

Pela escrita Deligny tentava traçar o corpo mínimo dos autistas em seus recuos, dando visibilidade a um corpo que não responde às forças hegemônicas de submissão. O que encontramos de mínimo gesto neste corpo é justamente sua esquiva as formas de adequação, sua indisponibilidade em atender às exigências da vida social. É um corpo que não está atento a toda informação que chega, que não responde a produtividade exigida, que não atende às regras de comportamento esperado.

Sendo assim, o território onde este corpo existe precisa ser instalado em um cotidiano de atividades para que seu gesto seja garantido. Em situações em que não se garante os objetos, movimentos, pontos de referência necessários a este modo de vida e alguma coisa se apresenta fora do lugar, é o próprio corpo do autista que se mostra desorientado, com o gesto impedido: "A menor alteração nesta ordem provoca angústia: uma porta entreaberta quando deveria estar fechada, um objeto esquecido. "Fotografe se você quiser, diz Jacques, mas sobretudo, não toque em nada" (DELIGNY, 2007, p. 852, tradução livre).

Para garantir a persistência deste modo de existir, era preciso não tocar em nada, permitindo que as coisas presentes no território fizessem sinal as crianças, fossem rastreadas por elas que vêem sem olhar. Como diz Deligny (2007): 
nossos olhos, seja de um objeto - qualquer - que pareça se tratar. Trata-se de coisas, mas estas pequenas coisas não são coisas quaisquer que nós percebemos (p. 1145, tradução livre).

O corpo da criança em seus mínimos gestos sinalizam um modo de composição do território permitindo que Deligny e nós possamos pensar em relações possíveis a serem estabelecidas, em modos de habitar, de sentir ou, se ousarmos dizer, de criar novas normas de vida, refazer um percurso e perceber outras saúdes.

Deligny ao recusar os excessos, se esquivar dos especialismos e afirmar uma condição de precariedade parece trazer pistas para acessar esta condição do corpo mínimo. Ele nos apresenta um modo de ver que envolve um recuo na experiência da interpretação, buscando ver por tentativas. Uma das tentativas que permitiu ver de outro modo a experiência de vida do autista foi a produção de mapas: "Quanto aos mapas? Trata-se de aprender a ver isto que não nos olha, isto que, à primeira vista, não interessa nem ao 'eu' nem ao 'ele'” (DELIGNY, 2007, p. 849, tradução livre).

Os mapas começaram a ser utilizados nesta experiência por diferentes motivos, mas uma das funções importantes era a de registrar o cotidiano de existência das crianças. Os mapas registravam traços dos trajetos, as variações dos gestos, destacavam acontecimentos particulares, indicavam a distribuição de objetos em uma determinada peça, enfim se apresentavam como linhas e coordenadas que indicavam um território de existência comum às crianças e aos cuidadores, chamados de presenças próximas.

Além do mapa, a escrita de Deligny também operava como uma das tentativas, buscando traçar os acontecimentos da vida partilhada, documentando os gestos, mas também misturando no mesmo texto fragmentos aleatórios de leituras que estava fazendo, de ideias ouvidas na rádio, para deste modo fazer passar algo que escapa aquilo que se quer dizer. Através da escrita, Deligny deixava passar o resto, presente no próprio gesto de escrever:

Não se pode negar: existe o escrever e existe o quê. O quê, o conteúdo do livro, o que ele dirá, o assunto a respeito do qual é escrito, tudo isso é evidentemente essencial; resta o escrever, que é aracniano (DELIGNY, 2008, p. 33-34). 
Criar Educação, Criciúma, v. 9, № 3, ago/dez. 2020 - PPGE - UNESC - ISSN 2317-2452

A escrita de Deligny tem um gesto que tenta se esquivar de comunicar ou explicar o que se passa com o autista e neste exercício consegue narrar o que resta, o que permeia este modo de vida singular.

Nesse sentido, podemos pensar, com Deligny (2007), em como narrar isso que se passa quando estamos desvencilhados de certo movimento do corpo pela exigência de não tocar em nada. O que começa a aparecer nas relações na natureza indicam o quanto este gesto de recuo dá visibilidade a outras existências que coexistem com o modo de vida que conhecemos. Como são enunciadas por notícias nos jornais, neste momento em que os humanos são obrigados a se recolherem em suas casas, pássaros fazem ninhos pelas ruas, águas cristalinas aparecem na ausência de turistas, outros sons, cheiros e cores estão presentes.

Dizemos que outras existências ganham visibilidade assim como nos tornamos sensíveis a outros gestos que dizem da nossa capacidade de afetar e sermos afetados pelo mundo. Nesse sentido, narrar o corpo mínimo "sem tocar em nada", pode ser uma tentativa de escrever sem explicar, de criar uma presença, que se recolhe e acolhe o encontro com o outro (pelo vídeo, pelo telefone, ao vivo a certa distância) com uma atenção a afetos mais imperceptíveis, menos frequentados.

A interdição do toque, na experiência da pandemia pode permitir um recuoaproximativo com nosso corpo mínimo. Este recuo pode se realizar em diversas ordens, por exemplo, esquecendo de algumas coisas que já sabemos, como os modos de cuidar que se tornaram mais instituídos e fragilizados, como os modos de pensar a relação entre saúde e doença, marcada por concepções do que seria o patológico e do que seria tratamento e cuidado através da correção de gestos e de certa anestesia da vida.

Nesse exercício de suspensão e subtração dos nossos fazeres cotidianos, das nossas perspectivas de atuação, nos modos de olhar nossa prática e nosso cuidado, de afirmar nossa vida, vamos tateando o que chega e o que sobra, acolhendo os restos. Uma recusa que se aproxima àquela do corpo imóvel da paciente com AVC. Uma recusa que exige de nós mesmos e do outro uma sensibilidade ainda não tocada.

\section{Todos seriam capazes de acessar este corpo mínimo?}


Criar Educação, Criciúma, v. 9, ํo 3, ago/dez. 2020 - PPGE - UNESC - ISSN 2317-2452

Será que por partilharmos desta situação de pandemia, vivendo recuos de diferentes tipos, todos nós temos condições de acessar e narrar o corpo mínimo?

Desvencilhando-nos dos entulhos das interpretações, com Deligny (1986), desvencilhando-nos dos entulhos informativos e da centralidade do sujeito, para ouvir uma história, como sugeriu Benjamin, "quanto mais o ouvinte se esquece de si mesmo, mais profundamente se grava nele o que é ouvido" (DELIGNY, 1986, p. 205), mais possível se torna selecionar o que chega em nós e perguntar pelo que somos sensíveis.

Se um dos movimentos para rastrear o corpo mínimo, ou seja, isso a que somos sensíveis neste momento de recuo, envolve uma defesa do bombardeio de ofertas informativas, selecionando o que chega ao corpo, ainda assim é preciso criar circunstâncias singulares e coletivas para este exercício.

Quando pensamos nos usuários de saúde e saúde mental, na paciente com o corpo paralisado, nas experiencias de restrição, ausência, nos limites impostos a cada um de nós neste período, podemos dizer que estamos sensíveis a muitas coisas, mas só em algumas circunstâncias conseguimos acessar, lembrar e conservar esta sensibilidade.

É preciso criar circunstâncias que envolvem certa escuta, alguma presença à distância, algum encontro virtual que rastreie os restos das memórias em cada vida. Por exemplo, circunstâncias que possam rastrear o que os usuários têm a dizer neste momento e como eles dizem; que possam através de uma conversa por telefone, ativar lembranças das vivências das quais eles mais sentem saudades; ajuda-los a narrar os rostos, cheiros e cores que ainda se conservam em suas memórias ou que aparecem em outras nuances.

Nas experiências de cuidado que inventamos neste momento podemos tentar narrar as variações contidas em uma experiência de isolamento, narrar a espessura do afeto que as distâncias produzem num corpo. O nosso corpo, o corpo dos usuários dos serviços de saúde, o corpo dos profissionais ganha outro compasso afetivo, vivendo com outra sensibilidade os efeitos da morte e dos novos modos de existência que se desenham.

Não sabemos dizer se o corpo é alargado, se ele ganha maior elasticidade, se é uma questão de profundidade ou superfície. O que suspeitamos é que, neste 
gesto de reconquistar o contato com a própria capacidade afetiva, que vinha sendo terceirizada pelo excesso de interpretações dos especialistas e pela invasão de demandas as quais os corpos precisavam responder, conserva-se uma memória dos mínimos gestos e aprende-se como selecionar o que fortalece e enfraquece o próprio corpo.

Avaliar os encontros envolve fazer seleções, mudar o território para que o corpo possa existir. Como o exemplo do autista, o corpo de cada um de nós, exige uma certa rede, um certo campo de relações que permita rastrear seus trajetos mais potentes. De todo modo, esta capacidade seletiva e avaliativa também precisa ser construída, demandando de quem cuida a invenção de novas estratégias.

Se um dos modos de acessar a sensibilidade pode ocorrer através da narrativa, tomando a escrita como território de cuidado, precisamos pensar quem escreve, como escreve, a que distância. Como profissionais e usuários podem experimentar este exercício, como cada um de nós experimenta narrar seu corpo mínimo?

Diferente das ofertas que recebemos a toda hora, a narrativa não se apresenta em fórmulas prontas, em um discurso pré-fabricado, em um estilo de escrita específico capaz de narrar os mínimos gestos. O aprendizado de como narrar depende de acolher esta precariedade, sustentar o recuo, os impedimentos da pandemia que permitem expressar num mínimo gesto a complexidade da sua potência vital. É na experiência mais sutil, que uma miríade de sensibilidades, que uma capacidade afetiva se apresenta em sua força.

Diríamos que a condição mínima de um corpo afirma o máximo da potência de pensar e agir. O que a princípio pareceria um paradoxo chama a atenção para que o aumento de uma potência, a grande capacidade afetiva de um corpo não se remete a excessos, a acoplagens de todos os tipos, a exaustão de afetações. Quando se busca preencher o tempo e o corpo neste momento de pandemia ocupando-se das infindáveis ofertas de lives, aulas online, filmes, músicas, espaços comunicativos, etc., muitas vezes, a sensação de vazio se mantém presente. Suspeitamos que o vazio, inseparável do excesso que tenta preenchê-lo, está relacionado a interdição do corpo mínimo, já que são entulhos que nada dizem do modo afetivo próprio a este corpo. 
Criar Educação, Criciúma, v. 9, № 3, ago/dez. 2020 - PPGE - UNESC - ISSN 2317-2452

Uma grande capacidade de afetar e ser afetado se expressa num gesto sutil, o qual empurra para longe todo o tipo de acúmulo e se esquiva da condição de corpo hiperconectado, mas também se esquiva de uma pura suspensão. $O$ mínimo gesto escapa do excesso e da falta, da sobrecarga e da sensação de que tudo parece interrompido.

Há uma oportunidade em certa paralisia que não se remete a impossibilidade de agir, mas a incapacidade de responder ininterruptamente às demandas. Em nossas práticas profissionais, nas experiências de cuidado podemos exercitar uma capacidade de "esquecer", "não-ouvir", "não-olhar", de agir para nada, como sugere Deligny (2007).

Passar de raspão em algumas camadas do presente, precarizar o território, ao invés de estar mergulhado, preenchido em demasia. Trata-se de não tocar em nada se esquivando não apenas do vírus, mas do que se tem a dizer sobre ele. Nesse sentido, narrar a experiência é fazê-lo do modo mais artesanal, com menos verborragia e dados, com um exigente exercício de traçar um gesto na escrita e acolher esta condição variante do nosso corpo e daqueles que cuidamos.

No caso das experiências de cuidado, narra-se para conservar a singularidade de vida daqueles que não podem, por si mesmo, narrá-las. Narrar é seguir e registrar os traços, ou seja, as camadas de sensibilidade que coexistem e não aparecem. Narra-se, portanto, uma experiência distinta do corpo operante, respondente, conectado de muitas maneiras, implicado em uma disposição adequada às demandas hegemônicas.

Narrar é um ato de recuperar o corpo que terceirizou sua capacidade de sentir, que havia esquecido de como tocar ou conquistar sua potência de vida. Narrar os gestos sutis dos corpos em experiências de confinamento, de exposição, de distanciamento que são sempre singulares é narrar com a pele, com uma palavra que toca aquilo a que somos sensíveis.

Certamente é um exercício que todos nós podemos experimentar, mas não o faremos sem garantir circunstâncias, que envolvem redes de cuidado, de partilha, espaços comuns de aprendizado que permitam descobrir a multiplicidade diferenciante e a variação contínua de cada corpo. 
Criar Educação, Criciúma, v. 9, nº 3, ago/dez. 2020 - PPGE - UNESC - ISSN 2317-2452

\section{Considerações finais}

Percorremos alguns caminhos que nos trazem pistas de como conservar a memória de um corpo mínimo, na medida em que este corpo expressa uma capacidade afetiva singular. Experimentando esquecer de algumas coisas para lembrar de outras, tentamos narrar um corpo, que escapa a supremacia do estado de prontidão, respondente, performático, hiperconectado, estado este que silenciou ou fez esquecer de outras sensibilidades.

Se a experiência de Deligny serve de inspiração para pensarmos em nosso modo de narrar o corpo mínimo no contexto atual de pandemia é porque ele nos traz pistas não apenas para aprender a narrar o resto, os mínimos gestos de um corpo, mas para criar um corpo capaz de narrar, capaz de escrever, capaz de instalar um território que acolha sensibilidades sutis.

A narrativa que tratamos aqui é aquela que faz durar uma memória do corpo mínimo. Narrar com palavras sensíveis, como aquelas de Dante que ainda ressoam para seus leitores contemporâneos, como gesto que acolhe as mínimas sutilezas de um corpo.

Desenvolvendo esta habilidade que segue o gesto, que toca a memória de afetos partilhados e ainda não traduzidos, alargamos sensações do corpo que até então estavam restritas em expressões de desamparo, angústia, fragilidade. Trata-se de sentir e tatear num ato de recolhimento, ato mínimo, quando o corpo não responde como antes, quando o corpo se recusa a produzir, quando o corpo aguenta um pouco mais até que alguma invisibilidade afetiva salte aos olhos.

Se somos "tocados" pelo fato de perder o direito ao toque, impedidos de agarrar com as mãos o leque de ofertas que produzia certo modo de existir, certo modo de subjetivação, também somos convidados a resgatar camadas de sensibilidade esquecida, através do exercício da escrita que pode deixar registrado para viventes de um futuro distante a memória de que em cada gesto mínimo coexistem muitos modos de existir.

O que este momento de pandemia nos faz lembrar é que, como diz Guimarães Rosa, "viver é etecetera" (ROSA, 2001, p.76) contemplando nesta peculiar palavra latina, que significa "e o resto", a infinidade de histórias, composições e gestos. Nesse sentido, o que não podemos esquecer é a pergunta a respeito de como narrar e 
conservar o resto, a força das muitas existências impedidas pelo modo de vida hegemônico que construímos.

\section{Referências}

ALIGUIERI, D. A Divina Comédia - Purgatório. Edição Bilingue. Tradução e notas de Ítalo Eugenio Mauro. São Paulo: Editora 34, 1998.

BENJAMIN, W. O narrador. In: Magia e Técnica, arte e política: ensaios sobre literatura e história da cultura. Trad. Sérgio Paulo Rouanet. 2. ed. São Paulo: Brasiliense, 1986. (Obras Escolhidas, v. 1).

BEZERRA JR., B. "A psiquiatria e a gestão tecnológica do bem-estar". In: FREIRE FILHO, João (org.). Ser feliz hoje: reflexões sobre o imperativo da felicidade. Rio de Janeiro, FGV, 2010.

BRUM, E. A menina quebrada e outras colunas. Porto Alegre: Arquipélago Editorial, 2013

CANGUILHEM, G. 0 normal e o patológico. 7 ed. Rio de Janeiro: Forense Universitária, 2017.

DELEUZE, G. Espinosa: Filosofia Prática. São Paulo: Escuta, 2002.

DELIGNY, F. Oeuvres. Édition établie et présentée par Sandra Alvarez de Toledo. Paris: Éditions Arachnéen, 2007.

DELIGNY, F. O Aracniano e outros textos. São Paulo: Editora N-1, 2008.

EHRENBERG, A. O culto da performance. São Paulo: Editora Ideias \& Letras, 2010. ESPINOSA, B. Ética. Trad. Grupo de Estudos Espinosanos. Coord. Marilena Chauí. São Paulo: EDUSP, 2018.

ORTEGA, F. O corpo incerto - Corporeidade, tecnologias médicas e cultura contemporânea. Rio de Janeiro: Garamond, 2008.

ROSA, G. Grande Sertão: Veredas. Rio de Janeiro: Nova Fronteira, 2001 